\title{
Malignant pertussis in infants: factors associated with mortality in a multicenter cohort study
}

Mathilde Coquaz-Garoudet ${ }^{1}$, Dominique Ploin ${ }^{1,2}$, Robin Pouyau' ${ }^{1}$, Yoav Hoffmann ${ }^{3}$, Julien-Frederic Baleine ${ }^{4}$, Benoît Boeuf ${ }^{5}$, Hugues Patural ${ }^{6}$, Anne Millet ${ }^{7}$, Marc Labenne ${ }^{8}$, Renaud Vialet ${ }^{9}$, Didier Pinquier ${ }^{10}$, Marie Cotillon ${ }^{10}$, Jérôme Rambaud ${ }^{11}$ and Etienne Javouhey ${ }^{1,12^{*}}$ (0)

\begin{abstract}
Background: Malignant pertussis (MP) affects young infants and is characterized by respiratory distress, perpetual tachycardia and hyperleukocytosis up to $50 \mathrm{G} /$, leading to multiple organ failure and death in $75 \%$ of cases. Leukodepletion may improve prognosis. A therapeutic strategy based on leukodepletion and extracorporeal life support (ECLS) according to different thresholds of leucocytes has been proposed by Rowlands and colleagues. We aimed at identifying factors associated with death and assess whether the respect of the Rowlands' strategy is associated with survival.
\end{abstract}

Methods: We reviewed all MP infants hospitalized in eight French pediatric intensive care units from January 2008 to November 2013. All infants younger than 3 months of age, admitted for respiratory distress with a diagnosis of pertussis and WBC count $\geq 50 \mathrm{G} / \mathrm{l}$ were recorded. Evolution of WBC was analyzed and an optimal threshold for WBC growth was obtained using the ROC-curve method. Clinical and biological characteristics of survivors and non-survivors were compared. Therapeutic management (leukodepletion and/or ECLS) was retrospectively assessed for compliance with Rowlands' algorithm (indication and timing of specific treatments).

Results: Twenty-three infants were included. Nine of 23 (40\%) died: they presented more frequently cardiovascular failure (100\% vs 36\%, $p=0.003$ ) and pulmonary hypertension (PHT; $100 \%$ vs $29 \%, p=0.002$ ) than survivors and the median [IQR] WBC growth was significantly faster among them (21.3 [9.7-28] G/l/day vs 5.9 [3.0-6.8] G/l/day, $p=0.007)$.

WBC growth rate $>12 \mathrm{G} / /$ day and lymphocyte/neutrophil ratio $<1$ were significantly associated with death $(p=0.001$ and $p=0.003$, respectively).

Ten infants (43\%) underwent leukodepletion, and seven (30\%) underwent ECLS. Management following Rowlands' strategy was associated with survival (100\% vs $0 \% ; p<0.001$, relative risk of death $=0.18,95 \%-\mathrm{Cl}[0.05-0.64]$ ).

Conclusions: A fast leukocyte growth and leukocytosis with neutrophil predominance during acute pertussis infection were associated with death. These findings should prompt clinicians to closely monitor white blood cells in order to early identify infants at risk of fatal outcome during the course of malignant pertussis. Such an early signal in infants

\footnotetext{
*Correspondence: etienne.javouhey@chu-lyon.fr

1 Service de Réanimation et Urgences Pédiatriques, Hospices Civils de Lyon, Hôpital Femme Mère Enfant, 59 Boulevard Pinel, 69677 Bron cedex,

France

Full list of author information is available at the end of the article
} in this article are included in the article's Creative Commons licence, unless indicated otherwise in a credit line to the material. If material is not included in the article's Creative Commons licence and your intended use is not permitted by statutory regulation or exceeds the permitted use, you will need to obtain permission directly from the copyright holder. To view a copy of this licence, visit http://creativeco mmons.org/licenses/by/4.0/. 
at high risk of death would increase feasibility of compliant care to Rowlands' strategy, with the expectation of a better survival.

Keywords: Malignant pertussis, Pediatric intensive care, Hyperleukocytosis, Leukodepletion, Risk factors of death

\section{Introduction}

Pertussis is one of the leading causes of bacterial infection-related death in pediatric intensive care units (PICU) in France for young infants [1]. Severe pertussis encompasses two different groups of patients hospitalized in PICU; those of the first group present recurrent apnea or apparent life-threatening events, and those of the second bronchopneumonia, some of whom will develop a critical course with refractory hypoxemia and pulmonary hypertension (PHT) [2]. The latter clinical form, termed "malignant pertussis" (MP) was first described in 1956 [3]. MP affects young infants before 3 months of age, and is characterized by an acute respiratory distress, associated with perpetual tachycardia and hyperleukocytosis up to $50 \mathrm{G} / \mathrm{l}$ leading to multiple organ failure $[4,5]$. Despite resuscitation and critical care, death occurs in up to $75 \%$ of cases [2, 4-9]. PHT and high white blood cell (WBC) count have been associated with a fatal outcome [2, 6, 7, 10-13]. Several "toxin-mediated" pathways are synergistic to explain fatalities: direct neurotoxicity, destruction of the respiratory epithelium inducing severe pneumonia, and profound systemic effects such as hyperleukocytosis by increasing circulating leukocyte mass [12-14]. Consequent hyper-viscosity result in arteriolar thrombosis with PHT, leading to cardiovascular failure and refractory hypoxemia $[13,15,16]$. These mechanisms were supported by post-mortem examination of lungs $[13,17]$ which led some physicians to propose leukodepletion (LD) with or without extracorporeal life support (ECLS) as adjunctive therapy to reduce this hyper-viscosity $[18,19]$, to decrease PHT, and to improve oxygenation [10], and therefore the prognosis. Murray et al. $[11,20]$ have demonstrated that infants with more severe illness had a more rapid rise in their total WBC count, suggesting that early WBC count monitoring would be useful to identify patients with poor outcome. Rowlands et al. [21] have proposed a therapeutic strategy based on cardiorespiratory failure (CRF) and WBC absolute count thresholds (50 G/l, $70 \mathrm{G} / \mathrm{l}$ and $100 \mathrm{G} / \mathrm{l}$ ), reinforcing the importance of $\mathrm{WBC}$ close monitoring to manage the disease.

The present study therefore aimed to identify factors associated with death in infants affected by MP, from the time of admission to the emergency department (ED) and up to $24 \mathrm{~h}$ after admission to the PICU. We hypothesized that a rapid WBC growth is associated with a more severe form and a high risk of death. We further aimed to determine whether management according to Rowlands' strategy is associated with survival.

\section{Material and methods \\ Design and setting}

A historical cohort study was conducted in eight French PICUs: Lyon, Marseille Hôpital Nord, Marseille la Timone, Montpellier, Grenoble, Saint-Etienne, ClermontFerrand, and Rouen. All infants younger than 3 months of age with positive RT-PCR for Bordetella pertussis, and admitted to a PICU for respiratory distress with hyperleukocytosis greater than $50 \mathrm{G} / \mathrm{l}$, at any stage of the disease, were included. Cases were identified from the PICUs database all MP cases hospitalized from January 2008 to November 2013 were retrospectively reviewed. Clinical, biological, and imaging data were collected in a retrospective review, and recorded anonymously. Approval from the regional review board was obtained (Comité de Protection des Personnes, number $\mathrm{QH}$ $3 / 2016)$ and the requirement for informed consent was waived.

\section{Variables recorded and definitions}

Demographic data, neonatal and postnatal history of the infant, season of the pertussis occurrence, vaccination status of the infant, and source of infection were collected. Clinical, biochemical, and hematological data were chronologically recorded during ED stay, at the time of transfer/admission to PICU, and during PICU stay. Worst values during the overall hospital stay were collected to characterize evolution of the disease. PHT was assessed on echocardiography findings. PHT was defined as mean pulmonary arterial pressure (mPAP) over $25 \mathrm{mmHg}$ estimated by using either the measure of tricuspid regurgitation velocity or pulmonary regurgitation velocity. The PHT was judged as severe when it was associated with echocardiographic signs of right ventricular failure or if the mPAP was iso- or supra-systemic. The pediatric logistic organ dysfunction (PELOD) score was used to assess severity at PICU admission. $\mathrm{SpO}_{2} / \mathrm{FiO}_{2}$ ratio was used as a proxy for the $\mathrm{PaO}_{2} / \mathrm{FiO}_{2}$ ratio [22] in order to assess the severity of the lung injury, and acute respiratory distress syndrome (ARDS) was defined according to the pediatric acute lung injury consensus conference (PALICC) definition. Organ failures were described according to the Goldstein classification [23]. Cardio-respiratory failure was 
defined as the association of respiratory failure according to Goldstein criterion with signs of cardiovascular failure according to Goldstein criterion or with signs of cardiac failure on echocardiography. The cardiorespiratory failure was judged severe when it required invasive ventilation and vaso-inotrope support.

$\mathrm{C}$-reactive protein (CRP), and when available procalcitonin (PCT), viral co-infection and bacterial superinfection were recorded.

We defined WBC growth as the absolute difference in WBC count over time in $\mathrm{G} / \mathrm{l} /$ day using the following formula: $\left(\mathrm{WBC}^{\prime}-\mathrm{WBC}\right) /\left(\mathrm{T}^{\prime}-\mathrm{T}\right)$, where $\mathrm{WBC}$ is the first value at $E D$ admission, $\mathrm{WBC}^{\prime}$ is the value at time of transfer to PICU (or within $24 \mathrm{~h}$ following admission), and $\left(\mathrm{T}^{\prime}-\mathrm{T}\right)$ is the interval between two blood samples in days. The lymphocyte/neutrophil ratio was computed and when WBC counts were maximal during ED and PICU stay; but WBC counts were no more considered after initiation of any specific procedure. The proportion of patients who had a lymphocyte/neutrophil ratio $<1$ was also recorded.

Treatment included antibiotics, intensive care drugs, and LD, i.e., exchange transfusion or leukopheresis, combined or not combined with ECLS.

Indications for specific interventions (LD and/or ECLS) were retrospectively assessed for compliance with Rowlands' algorithm in terms of indication and timing of specific treatments [21]. Briefly, we retained the following indications derived from the algorithm proposed by Rowlands: in case of CRF refractory to medical treatment, $\mathrm{ECMO}+\mathrm{LD}$ is indicated if $\mathrm{WBC}>50 \mathrm{G} / \mathrm{l}$, $\mathrm{ECMO} \pm \mathrm{LD}$ if $\mathrm{WBC}>30 \mathrm{G} / \mathrm{l}$, and standard respiratory ECMO for all other situations. In case of CRF responsive to medical treatment, urgent $\mathrm{LD}$ is indicated if WBC $>100 \mathrm{G} / \mathrm{l}$, if the infant has cardiac and respiratory failure with WBC $>70 \mathrm{G} / \mathrm{l}$, and if the infant has cardiac or respiratory failure and PHT with WBC $>50 \mathrm{G} / \mathrm{l}$; LD is indicated if WBC>50 G/l is associated with cardiac or respiratory deterioration; standard intensive care is indicated for all other situations. To assess the compliance according to the algorithm, the clinical and biological course of the disease was submitted independently to two expert physicians ( $\mathrm{YH}$ and $\mathrm{RP}$ ), blinded to the binary outcome ("non-survivor" or "survivor"). The experts had to categorize the indication according to Rowlands' algorithm [21]. Compliance or non-compliance were judged according to two criteria: (1) the realization of all indicated interventions, as any miss was considered as a deviation, and (2) interpreting the delay for the specific intervention: a delay $>24 \mathrm{~h}$ was considered as a deviation for any ECMO indication, or for any of the three LD indications flagged as "urgent".

\section{Statistical analysis}

Quantitative variables were reported as median and interquartile range [IQR]. Qualitative values were expressed as counts and percentages (\%). Percentages were compared using Fisher's exact test and distributions were compared using the Mann-Whitney $U$ test. A result was considered as significant if the probability of the random occurrence was less than $5 \%(p<0.05)$. WBC growth was studied using the receiver operating characteristic (ROC) method to test and separate the two groups with a threshold; The optimal cut-off value was defined as the value whose sensitivity and specificity were the closest to the value of the area under the ROC curve, and for which the absolute value of the difference between the sensitivity and specificity values was the smallest [24]. Agreement between experts was analyzed using Cohen's Kappa coefficient and interpreted according to Landis and Koch [25].

All statistical analyses were performed using IBM SPSS statistics ${ }^{\circledR}$ version 20.0 (IBM Armonk, NY, US).

\section{Results}

A total of 23 infants with positive RT-PCR for Bordetella pertussis, and criteria for MP were identified in the eight PICUs between 2008 and 2013 (Table 1). All infants received targeted macrolide treatment. Source of infection was identified in 18 cases (78\%): all contaminators were family members. Nineteen infants were not protected by vaccination: 17 (65\%) were not vaccinated; two infants received only 1 dose (data not available for the four remaining cases).

A total of 14 infants survived, and 9 (39\%) died after a median [IQR] delay since ED admission of 7 [4-12] days. Among nine non-survivors, seven infants died in the context of severe multiorgan failure combined in four of them with severe PHT; two infants died in the context of severe acute CRF subsequently put on ECLS with further complication of the procedure.

Broad-spectrum antibiotics were administered to 19 infants (83\%) for suspected bacterial superinfection. Bacteria were identified in 14 infants, including six nonsurvivors (43\%). Among the nine cases infected with enterobacteria or S. pneumonia, six were non-survivors (67\%). Nine infants presented viral co-infection, including four non-survivors. Four infants (17\%) presented neither superinfection nor viral co-infection, and all survived. Compared to survivors, non-survivors presented more cardiovascular failure ( $89 \%$ vs $21 \%, p=0.003$ ), more PHT $(100 \%$ vs $29 \%, p=0.002)$, and more kidney failure (100\% vs $36 \%, p=0.003$ ) (Table 2). During PICU stay, 17 infants (74\%) were intubated and $13(56 \%)$ required high frequency oscillation. Specific treatments included LD 
Table 1 Patient characteristics at the time of emergency department admission and at PICU admission

\begin{tabular}{|c|c|c|c|c|}
\hline & Non-survivors $(n=9)$ & Survivors $(n=14)$ & $p$ & $\begin{array}{l}\text { All patients } \\
(n=23)\end{array}$ \\
\hline \multicolumn{5}{|l|}{ A: At emergency department admission } \\
\hline Girl, $n(\%)$ & $5(56)$ & $6(43)$ & 0.7 & $11(48)$ \\
\hline Postmenstrual age, weeks, median [IQR] & 37 [36-39] & $38[35-40]$ & 0.6 & $38[36-40]$ \\
\hline \multicolumn{5}{|l|}{ Preterm, $n(\%)$} \\
\hline$<37$ weeks & $2(22)$ & $5(36)$ & 0.6 & $7(30)$ \\
\hline$<33$ weeks & $0(0)$ & $2(14)$ & 0.5 & $2(9)$ \\
\hline Birth weight, kg, median [IQR] & $2.5[2.3-3.0]$ & $2.9[2.6-3.6]$ & 0.1 & $2.9[2.5-3.5]$ \\
\hline Age, days, median [IQR] & $31[20-54]$ & $57[32-74]$ & 0.1 & $41[28-69]$ \\
\hline Weight, kg, median [IQR] & $3.5[2.9-4.0]$ & $3.8[3.1-5.9]$ & 0.2 & $3.6[3-4.6]$ \\
\hline Heart rate, bpm, median [IQR] & 176 [164-195] & 169 [155-179] & 0.3 & 170 [161-195] \\
\hline Respiratory failure, $n$ (\%) & $8(89)$ & $12(86)$ & 0.6 & $20(87)$ \\
\hline Sodium level, mmol/I, median [IQR] & 138 [137-139] & 135 [134-138] & 0.1 & 137 [135-139] \\
\hline C-reactive protein, mg, median [IQR] & $67[20-160]$ & $4[0-18]$ & 0.02 & $10[0-51]$ \\
\hline $\mathrm{pH}$, median [IQR] & $7.25[7.19-7.32]$ & $7.32[7.25-7.35]$ & 0.1 & $7.29[7.23-7.33]$ \\
\hline $\mathrm{PCO}_{2}, \mathrm{kPa}$, median $[\mathrm{IQR}]$ & $8.2[7.0-10.5]$ & $7.4[6.4-8.5]$ & 0.4 & $7.5[7.0-9.0]$ \\
\hline WBC count, G/l, median [IQR] & $26[19-50]$ & $36[20-58]$ & 0.6 & 32 [19-55] \\
\hline Neutrophil count, G/I, median [IQR] & $8[6-14]$ & $7[5-13]$ & 0.6 & $8[5-13]$ \\
\hline Lymphocyte count, G/l, median [IQR] & $17[10-30]$ & 23 [12-39] & 0.5 & $22[10-37]$ \\
\hline Lymphocyte/neutrophil ratio < 1, n (\%) & $1(11)$ & $1(7)$ & 1 & $2(9)$ \\
\hline \multicolumn{5}{|l|}{ B: At the time of transfer/admission to PICU } \\
\hline PELOD score, median [IQR] & $11[10-20]$ & $10[1-14]$ & 0.25 & $11[1-20]$ \\
\hline Heart rate, bpm, median [IQR] & 193 [181-202] & 179 [171-199] & 0.25 & 185 [174-200] \\
\hline $\begin{array}{l}\text { Need for emergency intubation before PICU } \\
\text { admission, } n(\%)\end{array}$ & $3(33)$ & $3(21)$ & 0.44 & $6(26)$ \\
\hline $\mathrm{SpO}_{2} / \mathrm{FiO}_{2}$ ratio, median [IQR] & $426[259-452]$ & $384[227-452]$ & 0.87 & $384[238-452]$ \\
\hline $\mathrm{pH}$, median [IQR] & $7.29[7.22-7.35]$ & $7.31[7.22-7.36]$ & 0.51 & $7.30[7.23-7.36]$ \\
\hline $\mathrm{pCO}_{2} \mathrm{kPa}$, median $[\mathrm{IQR}]$ & $7.3[6.4-9.4]$ & $7.19[6.34-8.5]$ & 0.68 & $7.3[6.4-9.0]$ \\
\hline Sodium level, mmol/I, median [IQR] & 129 [126-135] & $135[131-136]$ & 0.07 & $134[128-136]$ \\
\hline Lactate, mmol/l, median [IQR] & $2[2-4]$ & $2[1-3]$ & 0.29 & $2[1-3]$ \\
\hline WBC count, G/I, median [IQR] & $52[38-91]$ & $54[41-60]$ & 0.6 & $53[42-81]$ \\
\hline
\end{tabular}

IQR interquartile range; $p \mathrm{CO}_{2}$ partial pressure of carbon dioxide; $P E L O D$ pediatric logistic organ dysfunction; $\mathrm{SpO}_{2} / \mathrm{FiO}_{2}$ ratio pulse oximetry saturation/fraction of inspiratory oxygen; WBC white blood cell

(exchange transfusion in eight, leukopheresis in two), and ECLS in seven infants (Table 3).

\section{In the emergency department}

At ED admission, median [IQR] age was 41 [28-69] days, and median $[\mathrm{IQR}]$ weight was $3.6[3-4.6] \mathrm{kg}$. Twenty infants $(87 \%)$ presented with respiratory distress (Table $1 \mathrm{~A})$ and $14(61 \%)$ received oxygen during ED stay. Median CRP was 10 [0-51], median [IQR] WBC count at ED admission was 32 G/l [19-55]; lymphocyte/neutrophil ratio was $\geq 1$ in 21 infants, and $<1$ in two infants (Table 1A). Chest X-ray was performed in the ED for 22 infants, and found patchy infiltrates $(n=13)$, lobar infiltrates $(n=11)$, and/or atelectasis $(n=9)$; 4 were normal. All parameters were similar according to survival groups, except CRP which was significantly higher in non-survivors ( $67 \mathrm{vs} 4 \mathrm{mg} / \mathrm{l}, p=0.02$ ).

At the time of transfer to the PICU, all children presented with perpetual tachycardia, and heavy lymphocytosis; PELOD, pH, WBC and lymphocyte counts, and need for emergency intubation before PICU admission were similar in both groups (Table 1B).

\section{In the pediatric intensive care unit}

During PICU stay, median nadir of plasma sodium concentration was significantly lower in the non-survivors (122 vs $131 \mathrm{mmol} / \mathrm{l} ; p=0.003$ ). Median maximal PCT value was $19.0 \mu \mathrm{g} / \mathrm{l}[6.3-23.7]$ in 5 non-survivors vs $1.0 \mu \mathrm{g} / \mathrm{l}[0.2-4.3]$ in 9 survivors $(p=0.012)$. Median WBC growth was significantly faster among the non-survivors 
Table 2 Patient characteristics during PICU stay according to outcome

\begin{tabular}{|c|c|c|c|c|}
\hline & $\begin{array}{l}\text { Non-survivors } \\
(n=9)\end{array}$ & $\begin{array}{l}\text { Survivors } \\
(n=14)\end{array}$ & $p$ & $\begin{array}{l}\text { All patients } \\
(n=23)\end{array}$ \\
\hline Cardiovascular failure, $n(\%)$ & $9(100)$ & $5(36)$ & 0.003 & $14(61)$ \\
\hline Pulmonary hypertension, $n(\%)$ & $9(100)$ & $4(29)$ & 0.002 & $13(56)$ \\
\hline Kidney failure, $n(\%)$ & $8(89)$ & $3(21)$ & 0.003 & $11(48)$ \\
\hline Anuria, $n(\%)$ & $9(100)$ & $3(21)$ & $<0.001$ & $12(52)$ \\
\hline Neurological failure, $n(\%)$ & $3(33)$ & $6(43)$ & 1 & $9(39)$ \\
\hline Liver failure, $n(\%)$ & $5(56)$ & $2(14)$ & 0.049 & $7(30)$ \\
\hline Documented bacterial superinfection, $n(\%)^{\mathrm{a}}$ & $6(67)$ & $8(57)$ & 1 & $14(61)$ \\
\hline Documented viral co-infection, $n(\%)^{\mathrm{b}}$ & $4(44)$ & $5(36)$ & 1 & $9(39)$ \\
\hline Hematological failure, $n(\%)$ & $5(56)$ & $2(14)$ & 0.02 & $7(30)$ \\
\hline Secondary thrombopenia, $n$ (\%) & $7(78)$ & $6(43)$ & 0.19 & $13(57)$ \\
\hline Minimal sodium level, mmol/l, median [IQR] & $122[119-125]$ & 131 [129-135] & 0.003 & $130[122-135]$ \\
\hline Maximal lactate, mmol/l, median [IQR] & $9[3-16]$ & $3[2-4]$ & 0.02 & $3[2-9]$ \\
\hline Minimal pH, median $[\mathrm{IQR}]$ & $7.05[6.8-7.1]$ & $7.24[7.17-7.32]$ & 0.002 & $7.18[7.05-7.26]$ \\
\hline Maximal $\mathrm{pCO}_{2}, \mathrm{kPa}$, median [IQR] & $9.1[8.7-12.3]$ & $8.3[7.0-11.0]$ & 0.25 & $9.0[7.7-11.5]$ \\
\hline Maximal creatinine, $\mu \mathrm{mol} / \mathrm{l}$, median [IQR] & $81[49-110]$ & $27[23-51]$ & 0.002 & $40[25-82]$ \\
\hline Maximal C-reactive protein, mg/l, median [IQR] & $203[135-237]$ & 90 [7-205] & 0.11 & $135[30-217]$ \\
\hline Maximal procalcitonin, $\mu \mathrm{g} / \mathrm{l}$, median $[\mathrm{IQR}]$ & $19.0[6.3-23.7]$ & $1.0[0.2-4.3]$ & 0.012 & $3.3[0.5-19.3]$ \\
\hline WBC growth, G/I/day, median [IQR] & $21[10-28]$ & $6[3-7]$ & 0.007 & $6[3-17]$ \\
\hline Maximal WBC count, G/I, median [IQR] & 88 [63-95] & $65[53-81]$ & 0.12 & $71[56-91]$ \\
\hline Maximal neutrophils, G/l, median [IQR] & $41[23-47]$ & $25[16-37]$ & 0.14 & 26 [18-46] \\
\hline Maximal lymphocytes, G/I, median [IQR] & $33[26-34]$ & $33[28-39]$ & 0.83 & $32[28-37]$ \\
\hline Lymphocyte/neutrophil ratio < 1, n (\%) & $8(89)$ & $3(21)$ & 0.003 & $12(52)$ \\
\hline
\end{tabular}

a Stenotrophomonas maltophilia (1), SAMS (4), Escherichia coli (2), Klebsiella pneumoniae + Citrobacter koseri (1), Streptococcus pneumoniae (2), Enterobacter cloacae (1), other GNB (1), Haemophilus influenzae (1), Corynebacterium (1) were identified through tracheal (1), nasopharyngeal (7), blood culture (5), and bronchoalveolar lavage (1) samples

${ }^{b}$ Rhinovirus (3), Picornavirus (3), Bocavirus (1), Influenza B (1), RSV (3), were identified through nasopharyngeal samples (8)

$I Q R$ interquartile range; $p \mathrm{CO}_{2}$ partial pressure of carbon dioxide; $P E L O D$ pediatric logistic organ dysfunction; $P I C U$ pediatric intensive care unit; $S p \mathrm{O}_{2} / \mathrm{FiO}_{2}$ ratio pulse oximetry saturation/fraction of inspiratory oxygen; WBC white blood cell

Table 3 Therapeutics used during PICU stay, and compliance with Rowlands' algorithm [20]

\begin{tabular}{|c|c|c|c|c|}
\hline & Non-survivors $(n=9)$ & Survivors $(n=14)$ & $p$ & $\begin{array}{l}\text { All } \\
\text { patients } \\
(n=23)\end{array}$ \\
\hline Invasive ventilation, $n(\%)$ & $9(100)$ & $12(86)$ & 0.048 & $21(91)$ \\
\hline \multicolumn{5}{|l|}{ Treatment of pulmonary hypertension, $n(\%)$} \\
\hline Inhaled nitric oxide (INO) & $6(67)$ & $3(21)$ & 0.07 & $9(39)$ \\
\hline Sildenafil as an add-on to INO & $1(11)$ & $2(14)$ & 1 & $3(13)$ \\
\hline Renal replacement therapy, $n(\%)$ & $4(44)$ & $2(14)$ & 0.16 & $6(26)$ \\
\hline Corticosteroids, $n(\%)$ & $1(11)$ & $5(36)$ & 0.34 & $6(26)$ \\
\hline Broad-spectrum antibiotics & $9(100)$ & $10(71)$ & 0.13 & $19(83)$ \\
\hline Leukodepletion, $n(\%)$ & $3(33)$ & $7(50)$ & 0.7 & $10(43)$ \\
\hline Exchange transfusion, $n(\%)$ & $2(22)$ & $6(42)$ & & $8(35)$ \\
\hline Leukopheresis, $n(\%)$ & $1(11)$ & $1(7)$ & & $2(8)$ \\
\hline $\mathrm{ECLS}, n(\%)$ & $6(67)$ & $1(7)$ & 0.05 & $7(30)$ \\
\hline Compliance with Rowlands'algorithm, $n$ (\%) & $0(0)$ & $12(86)$ & $<0.001$ & $12(52)$ \\
\hline
\end{tabular}


compared to the survivors ( 21 vs $6 \mathrm{G} / \mathrm{l} /$ day, $p=0.007$ ). A lymphocyte/neutrophil ratio $<1$ was found in $11(48 \%)$ infants, and was more frequently found in non-survivors than in survivors $(89 \%$ vs $21 \%, p=0.003)$ (Table 2$)$.

Box plot of WBC growth shows unbalanced distribution according to survival groups (Fig. 1). ROC curve analysis indicated that WBC growth was strongly associated with death: the area under the curve (AUC) was 0.849 (95\%CI [0.653-1.000]; $p=0.006$ ), and the optimal cut-off value was obtained for a WBC growth of $12 \mathrm{G} / \mathrm{l} /$ day with a sensitivity of $78 \%$ and specificity of $93 \%$. Eight infants (35\%) had a WBC growth $>12$ G/l/day. Infants with WBC growth $>12$ G/l/day had significantly more frequently anuria $(87 \%$ vs $33 \%, p=0.03)$, had more frequently lymphocyte/neutrophil ratio $<1 \quad(87 \%$ vs $27 \%$; $p=0.009$ ).

Treatment included invasive ventilation in $91 \%$, LD in $43 \%$, mostly by exchange transfusion $(8 / 10)$, and ECLS in $30 \%$ (Table 3).

Indications according to Rowlands' algorithm consisted of an urgent intervention (urgent LD and/or ECMO) in 16 infants (70\%), the remaining consisted of three cases of non-urgent LD (13\%), and four cases of standard intensive care (17\%). Among the 11 cases of non-compliance to Rowlands' algorithm, nine died; for seven cases, a delay in the diagnosis of MP and/or on the indication of LD and/or ECLS was identified as a main cause of noncompliance, suggesting a lack of early recognition of the disease and its severity. In three of these seven cases, the lack of ECLS availability on site was a factor explaining the delay (cases 12, 17 and 22); in a further three cases, infants presented with such a severe picture (cases 2, 14 and 21 ) that the rapidity of worsening prevented the initiation of the specific intervention required. All of the

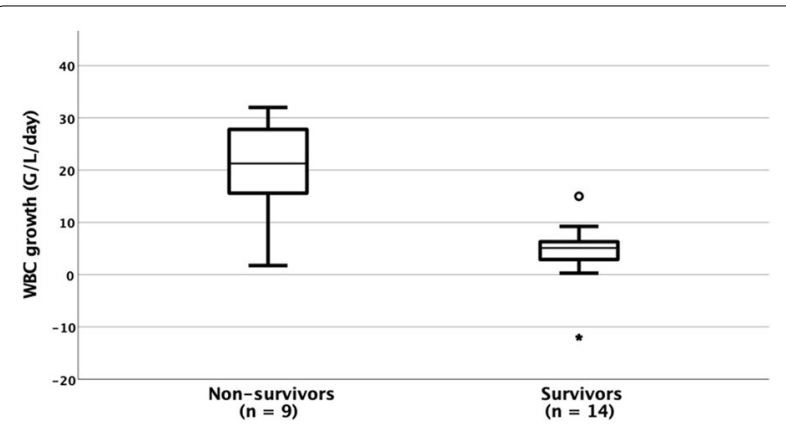

Fig. 1 Boxplot of WBC growth according to the patient outcome. Box and whiskers plot quartiles and the bold band inside the box is the median. The ends of the whiskers represent the minimum and maximum of all of the data, with the exception of the two outliers for the survivors' group, an open circle for the value over the $[\mathrm{Q} 3+1.5 *$ (interquartile range)], and an asterisk for the value under the $\left[\mathrm{Q} 1-3^{*}\right.$ (interquartile range)] latter three cases died and for two of these, ECLS was not available on site requiring a transfer to another center. Non-availability of ECLS on site was identified as the sole reason of deviation in one fatal case (case 9).

Thus, treatment was compliant in 12 cases (52\%); regarding agreement between experts, Cohen's Kappa coefficient was $0.91 \quad(p<0.001)$, a value considered "almost perfect" according to Landis and Koch interpretation [25].

Nineteen infants $(83 \%)$ presented one or more factors contributing to severity, including SAE from an ECMO procedure (cases 4, 9, and 17, i.e., 13\%: one limb ischemia, one thrombosis of the ECMO circuit, and one failure of the ECMO procedure); neither AE nor SAE were reported for LD. A total of 9 infants (39\%) were non-survivors (Table 4).

At the time of PICU admission, there was no significant difference between infants treated or not according to Rowlands' algorithm, even in terms of median [IQR] PELOD score (11 [10-20] vs 10 [1-18], $p=0.26)$. All infants $(100 \%, 8 / 8$ of whom 7 non-survivors) having WBC growth $>12 \mathrm{G} /$ day had a non-compliant treatment according to Rowlands' algorithm compared to $20 \%$ (3/15 of whom 2 non-survivors) in those who had a WBC growth $\leq 12 \mathrm{G} /$ day $(p<0.001$, relative risk of non-compliance $=0.20(95 \%$ CI $[0.07-0.55])$; all the 12 infants with WBC growth $\leq 12 \mathrm{G} /$ day and compliant treatment were survivors.

\section{Discussion}

In the present study, mortality in cases of MP was systematically associated with cardiovascular failure, PHT, and hyperleukocytosis. Moreover, WBC growth in nonsurvivors was three times faster than in those who survived, and a lymphocyte/neutrophil ratio $<1$ before $\mathrm{LD}$ as well as a higher median CRP at ED admission were both associated with death. A close monitoring of WBC count, WBC growth, and lymphocyte/neutrophil ratio may help physicians to decide when to transfer infants to PICU and when to initiate invasive specific interventions such as LD and/or ECLS.

In line with that reported elsewhere, the present study found that hyperleukocytosis was associated with death $[5-8,10,26,27]$. There was, however, some heterogeneity in the recruitment of patients and in definitions used for severe pertussis. It is of note that mortality found herein is coherent with the literature, being between that reported in studies recruiting from the total PICU population (ranging from 14 to $35 \%$ [2, $6,10,26])$ and those investigating specifically highrisk groups $(55 \%$ in patients with pneumonia, PHT, or receiving vasoactive drugs [4], 78\% in patients with pneumonia [2], and $71-72 \%$ in those receiving ECLS 
Table 4 Specific treatment indications, performed interventions, compliance to Rowlands'algorithm, severity factors, and outcome

\begin{tabular}{|c|c|c|c|c|c|c|}
\hline \multirow{2}{*}{$\begin{array}{l}\text { Indications } \\
\text { according to } \\
{[21]^{\mathrm{b}}}\end{array}$} & \multicolumn{2}{|c|}{$\begin{array}{l}\text { Performed } \\
\text { interventions }\end{array}$} & \multicolumn{2}{|c|}{ Compliance to the algorithm } & \multirow[t]{2}{*}{ Factors contributing to severity } & \multirow[t]{2}{*}{ Outcome } \\
\hline & LD & ECLS & Yes/no & If no, criteria for deviation & & \\
\hline Urgent LD & 2 & 0 & Yes & & PHT, KF, ARDS, seizures & Survivor \\
\hline Urgent LD & 1 & 0 & No & $>24$ h-delayed ECMO & Rapid worsening, ALF, KF, PHT, CPA & Non-survivor \\
\hline$V A-E C M O+L D$ & 0 & VA-ECMO & & No combined LD & Viral co-infection & \\
\hline Urgent LD & 0 & 0 & No & No LD & ALF, KF, ARDS, PHT & Non-survivor \\
\hline$V A-E C M O+L D$ & 0 & $\mathrm{~V} \rightarrow \mathrm{VA}-\mathrm{ECMO}$ & & $>24$ h-delayed ECMO & Viral co-infection & \\
\hline LD & 0 & 0 & No & No LD & Viral co-infection, PHT, ARDS & Non-survivor \\
\hline$V A-E C M O+L D$ & 0 & $\mathrm{~V} \rightarrow \mathrm{VA}-\mathrm{ECMO}$ & & $>24$ h-delayed ECMO, no combined LD & ECMO complication: limb ischemia & \\
\hline Urgent LD & 1 & 0 & Yes & & None & Survivor \\
\hline LD & 1 & 0 & & & & \\
\hline Urgent LD & 1 & 0 & Yes & & Seizures & Survivor \\
\hline LD & 1 & 0 & Yes & & Bacterial superinfection, viral co-infection & Survivor \\
\hline $\mathrm{SIC}$ & 0 & 0 & Yes & & Viral co-infection & Survivor \\
\hline \multirow[t]{2}{*}{$V A-E C M O+L D$} & \multirow[t]{2}{*}{1} & \multirow[t]{2}{*}{ VA-ECMO } & \multirow[t]{2}{*}{ No } & \multirow{2}{*}{$\begin{array}{l}\text { LD on time, but }>24 \text { h-delayed } \\
E C M O+\mathrm{LD}^{\mathrm{a}}\end{array}$} & PHT, ARDS, KF, bacterial superinfections & \multirow[t]{2}{*}{ Non-survivor } \\
\hline & & & & & $\begin{array}{l}\text { ECMO complication: circuit thrombosis, } \\
\text { extremities ischemia }\end{array}$ & \\
\hline VA-ECMO & 0 & VA-ECMO & Yes & & PHT, KF, bacterial superinfection & Survivor \\
\hline $\mathrm{SIC}$ & 0 & 0 & Yes & & None & Survivor \\
\hline Urgent LD & 0 & 0 & No & No LD & ARDS, KF, CPA & Non-survivor \\
\hline$V A-E C M O+L D$ & 0 & 0 & & No ECMO ${ }^{a}$, no combined LD & & \\
\hline \multirow[t]{2}{*}{ Urgent LD } & \multirow[t]{2}{*}{0} & \multirow[t]{2}{*}{0} & \multirow[t]{2}{*}{ No } & \multirow[t]{2}{*}{ No LD } & PHT, seizures & \multirow[t]{2}{*}{ Survivor } \\
\hline & & & & & Bacterial superinfection & \\
\hline$V A-E C M O+L D$ & 0 & 0 & No & No ECMO ${ }^{a}$, no combined LD & $\begin{array}{l}\text { Rapid worsening, ARDS, PHT, KF, bacterial } \\
\text { superinfection }\end{array}$ & Non-survivor \\
\hline LD & 1 & 0 & Yes & & Bacterial superinfection, ARDS, HTP, KF & Survivor \\
\hline Urgent LD & 0 & 0 & No & No LD & Viral co-infection, seizures & Survivor \\
\hline Urgent LD & 0 & 0 & No & > 24 h-delayed LD & $\begin{array}{l}\text { HTP, KF, ALF, CPA, seizures, viral co- } \\
\text { infection }\end{array}$ & Non-survivor \\
\hline$V A-E C M O+L D$ & 0 & VA-ECMO & & $>24$ h-delayed ECMO & $\begin{array}{l}\text { ECMO complication: failure of ECMO } \\
\text { procedure }\end{array}$ & \\
\hline $\mathrm{SIC}$ & 0 & 0 & Yes & & Bacterial superinfection, seizures, LTE & Survivor \\
\hline $\mathrm{SIC}$ & 0 & 0 & Yes & & None & Survivor \\
\hline LD & 1 & 0 & Yes & & None & Survivor \\
\hline$V A-E C M O+L D$ & 0 & 0 & No & No VA-ECMO ${ }^{a}$, no combined LD & $\begin{array}{l}\text { Rapid worsening, ARDS, PHT, bacterial } \\
\text { superinfection }\end{array}$ & Non-survivor \\
\hline Urgent LD & 1 & 0 & No & $>24$ h-delayed LD & ARDS, CPA, PHT, KF, ALF, seizures & Non-survivor \\
\hline$V A-E C M O+L D$ & 0 & VA-ECMO & & $>24$ h-delayed ECMO ${ }^{a}$, no combined LD & Bacterial superinfections & \\
\hline Urgent LD & 1 & 0 & Yes & & Bacterial superinfections, ARDS, seizures & Survivor \\
\hline
\end{tabular}

In case of refractory CRF: $E C M O+L F$ if $[W B C>50], E C M O \pm L F$ if $[W B C>30]$, and standard respiratory ECMO for all other situations

${ }^{a}$ ECLS not available on site: transfer to another center was required

${ }^{b}$ Indications refers to Rowlands' algorithm [21]. In case of responsive CRF: urgent LD if [WBC >100] or [WBC > 70+CF + RF] or [WBC > 70+(CF or RF) + PHT], LD if $[\mathrm{WBC}>50+$ (cardiac or respiratory deterioration)] and standard intensive care for all other situations

$A R D S$ acute respiratory distress syndrome; $A L F$ acute liver failure; $K F$ kidney failure; $C P A$ cardiopulmonary arrest; $E C L S$ extracorporeal life support; $L D$ leukodepletion; LTE life-threatening event; $P H T$ pulmonary hypertension; SIC standard intensive care; $V A-E C M O$ veno-arterial-extracorporeal membrane oxygenation; $V V$ - $E C M O$ venovenous-ECMO

$[9,28])$. Malignant pertussis was defined herein as WBC count $\geq 50 \mathrm{G} / \mathrm{l}$ in infants $<3$ months of age and it is noteworthy that WBC counts and severity parameters at PICU admission were not significantly different between survivors and non-survivors, which indicates that other factors should be explored to predict death. For instance, herein, WBC growth during PICU stay was significantly different between non-survivors and 
survivors; more specifically, WBC growth $>12 \mathrm{G} / \mathrm{l} /$ day was associated with PHT and death, whereas PELOD at PICU admission were similar between those with a growth $\leq 12 \mathrm{G} / \mathrm{l} /$ day and those with a growth $>12 \mathrm{G} / \mathrm{l} /$ day. This could suggest that WBC growth may precede clinical features and predict the severity of the disease more than a WBC count threshold. In addition, lymphocytosis is classically described as a consequence of pertussis infection [29], but for nearly $90 \%$ non-survivors neutrophils predominance occurred. This characteristic was also found by Ganeshalingham et al. [4] but the authors compared the subgroup of children with pneumonia, PHT, or receiving vasoactive drugs vs the others, without testing it against death. It may hypothesize that bacterial superinfection and/or severe inflammatory response associated with pertussis may increase neutrophil count. In line with this hypothesis, a high PCT level during PICU stay was associated with poor outcome (and there was also a trend towards this for CRP), and two-thirds non-survivors developed bacterial superinfection which is consistent with the recent suggestion made by Kazantzi et al. and Berger et al. $[6,30]$ that bacterial co-infection might contribute to the severity of illness and mortality. Another point of note is that all non-survivors developed PHT associated with respiratory and cardiovascular failure, which are well known factors associated with death $[9,12,27]$. This emphasizes the need for a systematic echocardiography at admission and during hospitalization to detect PHT and cardiac failure. Furthermore, all non-survivors developed anuria during their PICU stay and in such cases monitoring urine output and fluid overload estimation is crucial as it could lead to an earlier decision for renal replacement therapy.

Taken together, these parameters could be useful to identify early on infants who should be quickly transferred to a specialized PICU able to initiate LD and/or ECLS. In the present study, compliance with Rowlands' algorithm was associated with an improved outcome, as all patients treated according to the algorithm survived. Furthermore, infants who were not treated in accordance with Rowlands' algorithm were those who had the faster disease course. One of the possible explanations could be a late PICU admission in a more severe respiratory and/ or hematological failure preventing the application of LD at the right time. Indeed, among the 11 infants who were not treated in accordance with Rowlands' algorithm, seven were treated with a delay or did not receive specific interventions when indicated suggesting a non-recognition of the severity, whereas only three were identified as rapidly worsening not allowing timely interventions. Moreover, initial characteristics at PICU admission of infants who were not treated according to Rowlands' algorithm did not differ significantly from those treated in accordance with the strategy-except for WBC count and WBC growth that were higher. All infants with WBC growth $\leq 12 \mathrm{G} / \mathrm{l} /$ day did receive a treatment compliant with Rowlands' algorithm and survived, suggesting that assessment and monitoring was possible; conversely, when WBC growth was $>12 \mathrm{G} / \mathrm{l} /$ day, the clinical course may have prevented application of Rowlands' algorithm. This result confirms the prognostic value of leukocytes. An early determination of WBC growth and its monitoring may help PICU physicians to decide to initiate invasive treatment such as LD in order to improve the outcome, as it was already suggested by Nieves et al. [31]. The availability of ECLS on site was identified in the present study as a potential cofactor of non-compliance to Rowlands' algorithm contributing to a poor outcome. This result highlights the role of the orientation of infants at high risk of deterioration to a center where ECLS and LD are available, or the implementation of a mobile ECLS team able to put infants on ECMO and transfer them to the ECLS center. This may have implications in terms of regional organization of the health care system for infants with severe CRF secondary to pertussis infection.

This cohort is one of the largest reported and involved multiple centers in France. However, it is limited by the small sample size due to the rarity of the disease and its retrospective design; the results should be interpreted appropriately. In cases where infants were hospitalized in other hospitals before their PICU admission, previous biological analyses were not systematically done and consequently some data are missing. Rapidly evolving disease may explain how hard it is to define prognostic criteria. Protocol and therapeutic management-especially application of the Rowlands' algorithm or availability of technical equipment (such as ECLS) may differ from one center to another, and this can create measurement bias. To test the hypothesis of a better outcome if LD was performed earlier, a randomized controlled trial should be conducted, but the rarity of MP makes it difficult.

\section{Conclusion}

In infants with the diagnosis of severe pertussis, screening of inflammatory parameters, monitoring of leukocytes (not only absolute counts but growth per day) and lymphocyte/neutrophil ratio may help physicians to select early those requiring LD and/or ECLS. The consideration of these criteria along with the clinical course would increase compliance with Rowlands' strategy, with the expectation of better survival.

\section{Abbreviations}

ARDS: Acute respiratory distress syndrome; CRF: Cardio-respiratory failure; ECLS: Extracorporeal life support; ET: Exchange transfusion; ED: Emergency 
department; IQR: Interquartile range; KF: Kidney failure; LD: Leukodepletion; MP: Malignant pertussis; PELOD: Pediatric logistic organ dysfunction; PHT: Pulmonary hypertension; PICU: Pediatric intensive care unit; WBC: White blood cell.

\section{Acknowledgements}

The authors gratefully acknowledge the kind contribution of P. Robinson (DRCl, Hospices Civils de Lyon, Lyon, France) for help in manuscript preparation.

\section{Authors' contributions}

MC-G performed the literature search, collected data, prepared tables and figures, analyzed and interpreted data, and drafted the initial manuscript. DP designed the study, performed literature search, prepared tables and figures, analyzed and interpreted data, and drafted the initial manuscript. RP and YH performed literature search, analyzed and interpreted data. J-FB, BB, HP, AM, $M L, R V, D P, M C$, and JR, collected, analyzed and interpreted data. EJ conceptualized and designed the study, performed literature search, prepared tables and figures, analyzed, and interpreted data, and drafted the initial manuscript. All authors critically reviewed the manuscript for important intellectual content, approved the final manuscript as submitted. All authors read and approved the final manuscript.

\section{Funding}

None.

\section{Availability of data and materials}

The datasets used and/or analyzed during the current study are available from the corresponding author on reasonable request.

\section{Declarations}

\section{Ethics approval and consent to participate}

The protocol was approved by the Ethical Committee for Clinical Research (Comité de protection des Personnes Sud-Est III: QH 3/2016), and the requirement for informed consent was waived.

\section{Consent for publication}

Not applicable.

\section{Competing interests}

The authors declare that they do not have any competing interests. No external nor internal funding was used for the study.

\section{Author details}

${ }^{1}$ Service de Réanimation et Urgences Pédiatriques, Hospices Civils de Lyon, Hôpital Femme Mère Enfant, 59 Boulevard Pinel, 69677 Bron cedex, France. ${ }^{2}$ Laboratoire de Virologie et Pathologie Humaine - VirPath Team, Faculté de Médecine RTH Laennec, CNRS, UMR5308, INSERM U1111, Centre International de Recherche en Infectiologie (CIRI), École Normale Supérieure de Lyon, 7-11 rue Guillaume Paradin, 69372 Lyon cedex 08, France. ${ }^{3}$ Pediatric Intensive Care Unit, Western Galilee Medical Centre, PO Box 21, 22100 Nahariya, Israel. ${ }^{4}$ Département de Pédiatrie Néonatale et Réanimations, Hôpital Arnaud de Villeneuve, 371 Avenue du Doyen Gaston Giraud, 34295 Montpellier cedex 5, France. ${ }^{5}$ Service de Réanimation Pédiatrique, Centre Hospitalier Universitaire Estaing, 1 Place Lucie Aubrac, 63003 Clermont Ferrand cedex 1, France. ${ }^{6}$ Service de Réanimation Néonatale et Pédiatrique, Centre Hospitalier Universitaire de Saint-Etienne, Hôpital Nord, Pôle Mère-Enfant, 42055 Saint-Étienne cedex 2, France. ${ }^{7}$ Service de Médecine Néonatale et Réanimation Pédiatrique, Centre Hospitalier Universitaire de Grenoble, Hôpital Couple Enfant, Boulevard de la Chantourne, 38700 La Tronche, France. ${ }^{8}$ Service d'Anesthésie et de Réanimation Pédiatrique, Assistance Publique-Hôpitaux de Marseille, Hôpital de La Timone, 264 Rue Saint-Pierre, 13385 Marseille cedex 5, France. ${ }^{9}$ Service d' Anesthésie et de Réanimation Pédiatrique, Chemin Des Bourrely, Assistance Publique-Hôpitaux de Marseille, Hôpital Nord, 13915 Marseille cedex 20, France. ${ }^{10}$ Service de Pédiatrie Néonatale et Réanimation, Centre Hospitalier Universitaire de Rouen, Pôle Femme Mère Enfant, 1 rue de Germont, 76031 Rouen cedex, France. ${ }^{11}$ Service de Réanimation Néonatale Pédiatrique, Hôpital Trousseau, Assistance Publique-Hôpitaux de Paris, 26 Avenue du Dr
Arnold Netter, 75571 Paris, France. ${ }^{12}$ Université Claude Bernard, Lyon 1, 8 Avenue Rockefeller, 69008 Lyon, France.

Received: 9 October 2020 Accepted: 20 April 2021

Published online: 07 May 2021

\section{References}

1. Floret D, Group de pathologie infectieuse pédiatrique, Groupe francophone de réanimation et d'urgence pédiatrique. Pediatric deaths due to community-acquired bacterial infection. Survey of French pediatric intensive care units. Arch Pediatr. 2001;8(Suppl 4):705s-s711.

2. Namachivayam P, Shimizu K, Butt W. Pertussis: severe clinical presentation in pediatric intensive care and its relation to outcome. Pediatr Crit Care Med J. 2007;8:207-11.

3. Grumbach R, Guillard J, Kaplan M, Strauss P. Malignant pertussis in an infant of 11 months with diffuse necrosis of bronchial mucosa without notable involvement of the lung parenchyma. Arch Fr Pediatr. 1956:13:880-8.

4. Ganeshalingham A, McSharry B, Anderson B, Grant C, Beca J. Identifying children at risk of malignant Bordetella pertussis infection. Pediatr Crit Care Med. 2017;18:e42-7.

5. Petiot A, Devictor D, Huault G. Malignant pertussis. In: Journées Parisiennes de Pédiatrie. Flammarion Médecine-Sciences. Paris; 1983. p. $175-84$.

6. Berger J, Carcillo J, Shanley T, Wessel D, Clark A, Holubkov R, et al. Critical pertussis illness in children: a multicenter prospective cohort study. Pediatr Crit Care Med. 2013;14:356-65.

7. Mikelova LK, Halperin SA, Scheifele D, Smith B, Ford-Jones E, Vaudry $W$, et al. Predictors of death in infants hospitalized with pertussis: a case-control study of 16 pertussis deaths in Canada. J Pediatr. 2003;143:576-81.

8. Guillois B. Epidemiological and clinical findings of whooping cough in children hospitalized in pediatric intensive care unit between 1990 and 1994. Med Mal Infect. 1995;25:1272-80.

9. Halasa NB, Barr FE, Johnson JE, Edwards KM. Fatal pulmonary hypertension associated with pertussis in infants: does extracorporeal membrane oxygenation have a role? Pediatrics. 2003;112(6.1):1274-8.

10. Pierce C, Klein N, Peters M. Is leukocytosis a predictor of mortality in severe pertussis infection? Intensive Care Med. 2000;26:1512-4.

11. Murray EL, Nieves D, Bradley JS. Characteristics of severe Bordetella pertussis infection among infants $\leq 90$ days of age admitted to pediatric intensive care units. J Pediatr Infect Soc. 2009;2:1-6.

12. Goulin GD, Kaya KM, Bradley JS, Gargas J, Mason WH, Lehman D, et al. Severe pulmonary hypertension associated with shock and death in infants infected with Bordetella pertussis. Crit Care Med. 1993;21:1791-4.

13. Paddock CD, Sanden GN, Cherry JD, Gal AA, Langston C, Tatti KM, et al. Pathology and pathogenesis of fatal Bordetella pertussis infection in infants. Clin Infect Dis. 2008:47:328-38.

14. Williams GD, Numa A, Sokol J, Tobias V, Duffy BJ. ECLS in pertussis: does it have a role? Intensive Care Med. 1998;24:1089-92.

15. Donoso A, Arriagada D, Cruces P, Díaz F. Severe pertussis: state of the art. Rev Chil Infectologia. 2012;29:290-306.

16. Pooboni S, Roberts N, Westrope C, Jenkins DR, Killer H, Pandya HC, et al. Extracorporeal life support in pertussis. Pediatr Pulmonol. 2003;36:310-5.

17. Sawal M, Cohen M, Irazuzta JE, Kumar R, Kirton C, Brundler M-A, et al. Fulminant pertussis: a multi-center study with new insights into the clinico-pathological mechanisms. Pediatr Pulmonol. 2009:44:970-80.

18. Romano MJ, Weber MD, Weisse ME, Siu BL. Pertussis pneumonia, hypoxemia, hyperleukocytosis, and pulmonary hypertension: improvement in oxygenation after a double volume exchange transfusion. Pediatrics. 2004;114:e264-6.

19. Kuperman A, Hoffmann Y, Glikman D, Dabbah H, Zonis Z. Severe pertussis and hyperleukocytosis: is it time to change for exchange? Transfusion. 2014;54:1630-3.

20. Murray EL, Nieves D, Bradley JS, Gargas J, Mason WH, Lehman D, et al. Characteristics of severe bordetella pertussis infection among infants $\leq 90$ days of age admitted to pediatric Intensive Care Units—-Southern California, September 2009-June 2011. J Pediatr Infect Dis Soc. 2013;2(1):1-6. 
21. Rowlands HE, Goldman AP, Harrington K, Karimova A, Brierley J, Cross N, et al. Impact of rapid leukodepletion on the outcome of severe clinical pertussis in young infants. Pediatrics. 2010;126:e816-27.

22. Rice TW, Wheeler AP, Bernard GR, Hayden DL, Schoenfeld DA, Ware $\mathrm{LB}$, et al. Comparison of the $\mathrm{SpO}_{2} / \mathrm{FIO}_{2}$ ratio and the $\mathrm{PaO}_{2} / \mathrm{FIO}_{2}$ ratio in patients with acute lung injury or ARDS. Chest. 2007;132:410-7.

23. Goldstein B, Giroir B, Randolph A. International pediatric sepsis consensus conference: definitions for sepsis and organ dysfunction in pediatrics. Pediatr Crit Care Med. 2005:6:2-8.

24. Unal I. Defining an optimal cut-point value in ROC analysis: an alternative approach. Comput Math Methods Med. 2017;2017:3762651.

25. Landis JR, Koch GG. The measurement of observer agreement for categorical data. Biometrics. 1977;33:159-74.

26. Palvo F, Fabro AT, Cervi MC, Aragon DC, Ramalho FS, de Carlotti APCP. Severe pertussis infection: a clinicopathological study. Medicine. 2017;96:e8823.

27. Vitek CR, Pascual FB, Baughman AL, Murphy TV. Increase in deaths from pertussis among young infants in the United States in the 1990s. Pediatr Infect Dis J. 2003;22:628-34.
28. Domico M, Ridout D, MacLaren G, Barbaro R, Annich G, Schlapbach L, et al. Extracorporeal membrane oxygenation for pertussis: predictors of outcome including pulmonary hypertension and leukodepletion. Pediatr Crit Care Med. 2018;19:254-61.

29. George TI. Malignant or benign leukocytosis. Hematol Am Soc Hematol Educ Program. 2012;2012:475-84.

30. Kazantzi MS, Prezerakou A, Kalamitsou SN, Ilia S, Kalabalikis PK, Papadatos $J$, et al. Characteristics of Bordetella pertussis infection among infants and children admitted to paediatric intensive care units in Greece: a multicentre, 11-year study. J Paediatr Child Health. 2017;53:257-62.

31. Nieves D, Bradley JS, Gargas J, Mason WH, Lehman D, Lehman SM, et al. Exchange blood transfusion in the management of severe pertussis in young infants. Pediatr Infect Dis J. 2013;32:698-9.

\section{Publisher's Note}

Springer Nature remains neutral with regard to jurisdictional claims in published maps and institutional affiliations.

\section{Submit your manuscript to a SpringerOpen ${ }^{\circ}$ journal and benefit from:}

- Convenient online submission

- Rigorous peer review

- Open access: articles freely available online

- High visibility within the field

- Retaining the copyright to your article

Submit your next manuscript at $\boldsymbol{\nabla}$ springeropen.com 